\title{
A COMMUNITY SURVEY ON THE PERFORMANCE OF THE PHILIPPINE NATIONAL POLICE (PNP) IN THE PROVINCE OF ALBAY
}

Deri Ritzelda A. ${ }^{*} \bowtie(i D)$, Gilbas Sherill A. ${ }^{2}$ (iD), Dio Ryan V. ${ }^{3}$ iD

${ }^{* 1,2,3}$ School of Graduate Studies, Sorsogon State Collage, Philippines

DOI: https://doi.org/10.29121/granthaalayah.v8.i12.2020.2784

Article Type: Research Article

Article Citation: Deri Ritzelda A., Gilbas Sherill A., and Dio Ryan V.. (2020). A COMMUNITY SURVEY ON THE PERFORMANCE OF THE PHILIPPINE NATIONAL POLICE (PNP) IN THE PROVINCE OF ALBAY. International Journal of Research GRANTHAALAYAH, 8(12), 270-278. https://doi.org/10.29121/granthaa layah.v8.i12.2020.2784

Received Date: 15 November 2020

Accepted Date: 31 December 2020

Keywords:

Community Survey

PNP Performance

Trust Rating

Respect Rating

Safety and Security

Albay Province

\section{ABSTRACT}

This paper highlights the trust, respect, safety and security ratings of the community to the Philippine National Police (PNP) in the Province of Albay. It presents the sectoral ratings to PNP programs. The survey utilized a structured interview with 200 sample respondents from Albay coming from different sectors. Male respondents outnumbered female respondents. The majority of the respondents are 41-50 years old, at least high school graduates and are married. The respondents gave the highest net rating on respect, followed by net rating on trust and the lowest net rating on safety and security on the performance of the PNP. Moreover, a high net rating on commitment of support to the identified programs of the PNP was also attained from the respondents. The highest net rating of support is given to the PNP's anti-illegal drugs program, followed by antiterrorism, anti-riding in tandem and anti-illegal gambling programs. The ratings of the PNP obtained from the different sectors of the community may be explained by the respondents' nature of work or professions. Moreover, recommendations given by most of the respondents are focused on safety and security. The negative comments from the respondents may be considered to improve the PNP as an organization.

\section{INTRODUCTION}

Republic Act No. 8551 states that the Philippine National Police (PNP) shall be a community and serviceoriented agency responsible for the maintenance of peace and order and public safety. It shall be so organized to ensure accountability and uprightness in police exercise of discretion as well as to achieve efficiency and effectiveness of its members and units in the performance of their functions. One of its four perspectives that are aligned to its mandates and functions as a safekeeping agency is working in partnership with a responsive community at the national, regional and local levels. These communities must be engaged so that a working partnership can be forged in attaining a "safer" environment.

The Philippine National Police's (PNP) office in Bicol region has its online survey on performance evaluation as part of the PNP Patrol Plan 2030. [1] It was used in the region to facilitate the conduct of a community engagement survey to measure public understanding and perception of the performance of the PNP in Bicol. However, the observation of the PNP audit team that the police in uniform acted as enumerators and that their respondents are

(C) 2020 The Author(s). This is an open access article distributed under the terms of the Creative Commons Attribution License, which permits unrestricted use, distribution, and reproduction in any medium, provided the original author and source are credited. 
Deri Ritzelda A., Gilbas Sherill A., and Dio Ryan V.

contained only to those who visited the Provincial Police Office (PPO) to air their complaints created a doubtful result. To come up with a credible survey result on community approval rating on the performance of the PNP in the Bicol region that will be acceptable to its stakeholders, the PNP regional office forges an agreement with Sorsogon State College (SSC), an academic institution and a neutral body to conduct the community survey along the PNP's delivery of programs and services. It determined the ratings of the community along areas of trust, respect, safety and security. It also determined the community's rating on the commitment to support the PNP on the implementation of its programs and services along anti-illegal drugs, anti-terrorism, anti-riding in tandem, and antiillegal gambling.

The regional survey gained an over-all average net rating of $82.62 \%$ from Bicolanos in the PNP Bicol's delivery of their programs and services. This result is way higher from the +55 net rating of Filipinos to the PNP in 2014. [2] However, it may not draw out enough understanding of the provincial perspective, specific to Albay. Hence to give a different insight on how the province may strategize and behave in accordance with the norms and culture of its constituents, this study magnifies and analyzes the result obtained in the province of Albay.

Albay is one of the provinces in the Bicol region, the residents of which are called Albayanos. It has a total land area of 2,554.06 square kilometers, comprising 3 cities and 15 towns. Albay offers interesting places for foreign and local tourists alike. Albay's major industry is agriculture and its accessibility is available via air, water and land. Albay hosts several public regional offices including those of the national police forces.

The PNP Albay fosters the same challenge of enforcing the law, preventing and controlling crimes, maintaining peace and order, and ensuring public safety with the other provinces. This paper intends to highlight the trust, respect, safety and security ratings of the community to the PNP in the Province of Albay. It also aims to highlight the sectoral commitment of support to PNP programs and feedbacks to the PNP. Specifically, it focused on the following objectives: 1.) Determine the demographic profile of the respondents according to a. gender, b. civil status, c. age, and d. educational attainment, 2.) Determine the ratings of the Albayanos and their significant comments on a. Trust, b. Respect, c. Safety and Security, d. Commitment of Support to the PNP 3.) Determine the sectoral ratings on the identified variables.

\section{METHODOLOGY}

This study utilized a descriptive type of research method. The survey was conducted to gather the ratings and feedbacks on the PNP performance along trust, respect, and safety and security from the different sectors in the province of Albay. The enumerators in the conduct of the survey utilized a structured interview with the identified sectors. A total of 200 sample respondents from Albay were involved in the survey, which is based on a sample of 1,178 in the regional survey. The topographical quadrant in figure 1 was the basis for the random selection of the four municipalities namely Daraga, Libon, Bacacay and Tabaco City as the area of analysis. Each municipality was allotted 50 respondents incorporating the 13 sectors; five parents, five youth, three business sector, five agricultural, five transportation, three religious, four private employees, four government employee, four elected government officials, one judiciary, one media, five informal workers, and five from the academe. These sectors were purposively selected in coordination with the Local Government Unit (LGU) but the respondents per sector were selected randomly. A three-part survey-questionnaire was the main instrument used in the study. The first part of the questionnaire pertains to the demographic profile of the respondents. The second part is about the community ratings along trust, respect, safety and security on PNP. The third part of the questionnaire focuses on the commitment of support to the PNP against illegal drugs, terrorism, riding in tandem, and illegal gambling. The questionnaire also includes open-ended questions that capture the comments and suggestions regarding the implementation of the PNP programs, projects, and activities. The conduct of the dry run was made in Legaspi City and Malilipot, Albay. 


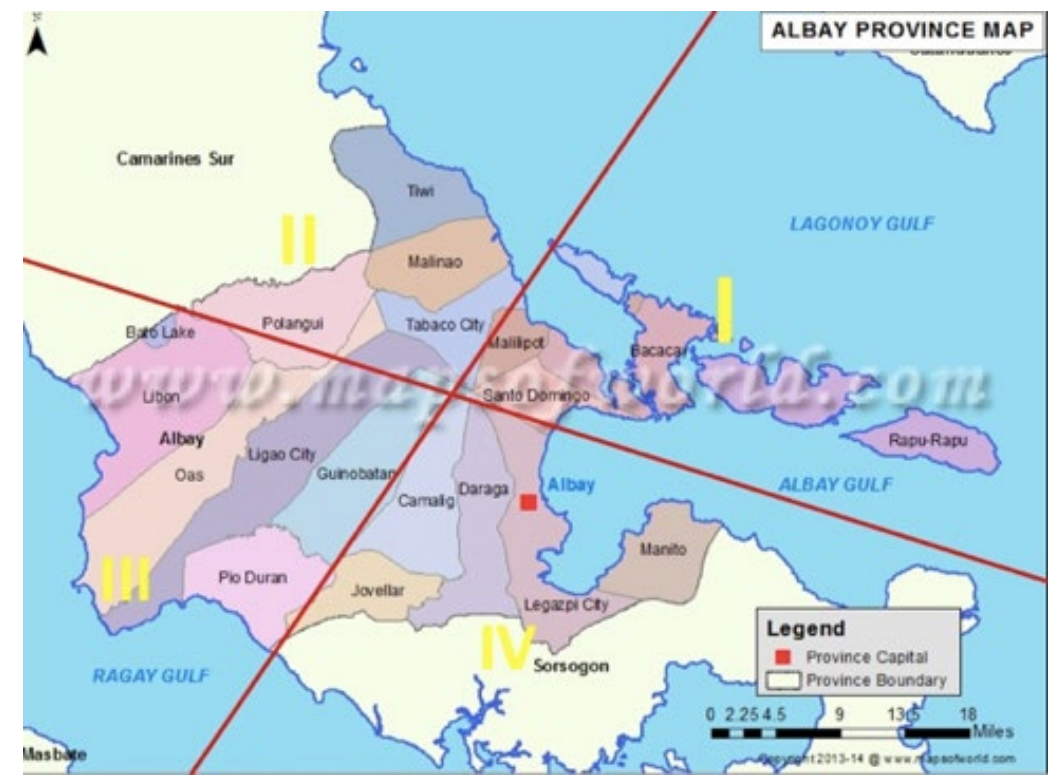

Figure 1: Topographical Quadrant for Albay

Frequency count, mean and percentages are the descriptive statistical tools used in describing the demographic profile of the respondents and the community ratings along trust, respect, safety and security. The frequencies and percentages results were also used to identify the net ratings given by the community to the PNP. Net rating is determined by subtracting the "unfavorable" responses from the "favorable" responses. The Interpretation and analysis of the result of the open ended-questions were based on the thematic coding approach used in the qualitative type of research.

\section{FINDINGS AND DISCUSSIONS}

\subsection{THE DEMOGRAPHIC PROFILE OF THE RESPONDENTS}

The respondents were from the municipalities of Daraga, Libon, Bacacay and Tabaco City. Daraga is an inland and a first-class municipality while Bacacay is an islet and a second-class municipality. Tabaco is a fourth class city while Libon is partly coastal and partly agricultural but is a first-class municipality. All of the respondents went to schooling, however, $57 \%$ of them are not college graduate.

Table 1 shows that the Majority or $56.50 \%$ of the respondents are male while $43.50 \%$ are female. The majority or $23.50 \%$ of the respondents are from 41-50 years old while the lowest percentage is from the age range of 20 years old and below.

Table 1: Sex and Age

\begin{tabular}{|c|c|c|c|c|c|c|}
\hline Age (Yrs old)/Sex & Male & $\%$ & Female & $\%$ & Total & $\%$ \\
\hline 20 \& below & 8 & $4.00 \%$ & 10 & $5.00 \%$ & 18 & $9.00 \%$ \\
\hline $21-30$ & 24 & $12.00 \%$ & 18 & $9.00 \%$ & 42 & $21.00 \%$ \\
\hline $31-40$ & 28 & $14.00 \%$ & 18 & $9.00 \%$ & 46 & $23.00 \%$ \\
\hline $41-50$ & 29 & $14.50 \%$ & 18 & $9.00 \%$ & 47 & $23.50 \%$ \\
\hline $51-59$ & 14 & $7.00 \%$ & 14 & $7.00 \%$ & 28 & $14.00 \%$ \\
\hline 60 \& above & 10 & $5.00 \%$ & 9 & $4.50 \%$ & 19 & $9.50 \%$ \\
\hline Total & 113 & $56.50 \%$ & 87 & $43.50 \%$ & 200 & $100 \%$ \\
\hline
\end{tabular}

It also reveals that there are more male respondents with ages 21years old to 50 years old as well as with ages 60 years old and above. Females outnumbered males only in the 20 years old and below age range. This result is consistent with the sex ratio of 1010 males for every 1000 females in the 2017 demographics of the Philippines indicating that males are greater in number than their female counterparts. [3] It can also be noted that the number 
Deri Ritzelda A., Gilbas Sherill A., and Dio Ryan V.

of male respondents significantly increases from the youngest age to 50 years old but drastically drop down from ages 51 years old and up. In contrary to this age trend, the number of females slowly decreased when they reached the same age ranges. PSA provided data showing that the sex ratio declines at the age of 55 for all the census years 2000-2010 and noted that there had been a lesser number of males than females. [4]

Table 2: Age and Civil Status

\begin{tabular}{|c|c|c|c|c|c|c|c|c|c|c|}
\hline Age (Yrs old)/CS & $\mathrm{S}$ & $\%$ & $\mathrm{M}$ & $\%$ & $\mathrm{SE}$ & $\%$ & $\mathrm{~W}$ & $\%$ & Total & $\%$ \\
\hline 20 \& below & 18 & $9.00 \%$ & 0 & $0.00 \%$ & 0 & $0.00 \%$ & 0 & $0.00 \%$ & 18 & $9.00 \%$ \\
\hline $21-30$ & 31 & $15.50 \%$ & 10 & $5.00 \%$ & 1 & $0.50 \%$ & 0 & $0.00 \%$ & 42 & $21.00 \%$ \\
\hline $31-40$ & 11 & $5.50 \%$ & 35 & $17.50 \%$ & 0 & $0.00 \%$ & 0 & $0.00 \%$ & 46 & $23.00 \%$ \\
\hline $41-50$ & 1 & $0.50 \%$ & 45 & $22.50 \%$ & 1 & $0.50 \%$ & 0 & $0.00 \%$ & 47 & $23.50 \%$ \\
\hline $51-59$ & 3 & $1.50 \%$ & 21 & $10.50 \%$ & 1 & $0.50 \%$ & 3 & $1.50 \%$ & 28 & $14.00 \%$ \\
\hline 60 \& above & 1 & $0.50 \%$ & 16 & $8.00 \%$ & 0 & $0.00 \%$ & 2 & $1.00 \%$ & 19 & $9.50 \%$ \\
\hline Total & 65 & $32.5 \%$ & 127 & $63.5 \%$ & 3 & $1.50 \%$ & 5 & $2.50 \%$ & 200 & $100 \%$ \\
\hline
\end{tabular}

Legend: S-Single, M-Married, SE-Separated, W-Widow(er)

Most of the single respondents are below 31 years old while most of the married respondents are more than 30 years old. Most widow(er) belonged to the age group 51 years old and above. The result connotes that Albayanos marry later in age as compared with the average marrying age in the Philippines. The average marrying age for the last 10 years is from 20 to 29 years old. The female marries at the age of 20-24 years old while its male counterpart marries at the age of 25-29 years old. [5]

\subsection{THE NET RATINGS ON TRUST, RESPECT, SAFETY AND SECURITY AND COMMITMENT OF SUPPORT TO THE PNP}

Law enforcement executives are constantly striving to preserve a positive, ethical image of their departments to the public they are sworn to serve and protect. However, several reasons may influence the perception of the community of its local police. Table 4 reflects the perception of the community on trust, respect, safety and security to the PNP.

Table 3 revealed that Albayanos gave the highest net rating of $92.50 \%$ on respect, followed by a net rating of $81 \%$ on trust and the lowest net rating of $73 \%$ on safety and security.

Table 3: Net Rating of the Respondents on Trust, Respect, Safety and Security

\begin{tabular}{|c|c|c|c|c|c|c|c|}
\hline & Favorable & $\%$ & Unfavorable & $\%$ & Undecided & $\%$ & Net Rating \\
\hline Trust & 168 & $84 \%$ & 6 & $3 \%$ & 26 & $13 \%$ & $81 \%$ \\
\hline Respect & 187 & $93.5 \%$ & 2 & $1 \%$ & 11 & $5.5 \%$ & $92.5 \%$ \\
\hline Safety \& Security & 158 & $79 \%$ & 12 & $6 \%$ & 30 & $15 \%$ & $73 \%$ \\
\hline Average & 171 & $85.50 \%$ & 6.67 & $3.33 \%$ & 22.33 & $11.17 \%$ & \\
\hline
\end{tabular}

Respect: Respect ratings centered on the community's respect to PNP and PNP respect to the community. The majority or $93.5 \%$ of the respondents in Albay showed favorable respect rating to the PNP with only $1 \%$ unfavorable. These findings may be supported by the qualitative treatment of responses from the respondents. The positive comments came from respondents in Bacacay and Libon areas. They stated that "The policemen in our town are kind and courteous"; "Police works nicely"; and some are good police officers. On the other hand, the negative comments came from the four covered areas but the most hailed from the area of Daraga. The respondents' most common complaints include "Lack of respect to those who committed mistakes"; "Slow in response to some remote places"; and "Some policemen only stand and sit without doing anything". The values and character of a person command respect in his social environment. Police officers who manifested such characteristics may get positive approval from their community. The harmonious relationship with others while performing the jobs when on duty or off duty may add up to respect from the community. Police officers are public servants and are expected to adhere to higher professional and ethical standards than most public servants do. In fact, the public scrutinizes police officers more than most other professions, either because they are cynical or hope to catch them screwing up, unskillful in their 
jobs, procrastinating, violating laws or because they are hopeful and are looking for a good example and a strong leader. Accordingly, a single uncouth act committed by a single unprofessional police officer can impact the entire law enforcement profession. [6] The public makes no distinction between police officers; all of them look and act the same in the eyes of the average citizen.

Trust: Moreover, trust ratings focus on the PNP's initiatives in improving programs against criminality and the community's confidence towards the PNP. The majority or $84 \%$ of the respondents in Albay showed a favorable trust rating to the PNP with 3\% unfavorable. These findings maybe supported by the qualitative treatment of responses from the respondents. The respondents gave positive feedback on trust, giving majority comments like, "good and excellent job "to the police. One of the respondents commented, "So far, in our locality, I can see that our policemen are really doing their job accordingly". Others have stated, "Policemen in our place are kind and ready to help". On the other hand, negative feedbacks focused on some policemen who are allegedly involved on drugs and bribery. They include: "Remote places are not frequently visited"; "Some policemen asked for bribe or inducement"; and "Some policemen are involved in illegal drugs and extrajudicial killings" among others. Police officers can build trust among their community through transparency. The community must be able to witness that police policies and procedures were used and implemented correctly. Any police unit that followed the established procedures and holds their officers accountable when the procedures are not followed can assure a higher approval rating on trust to the PNP. Thus, police officers are afforded awesome authority to carry out their duties. However, any excessive use of that authority, abuse of power, or failure to fulfill their duties can erode public trust and reduce or destroy their credibility within the communities they serve. Every member of a police department must understand that he represents the entire agency, that personal conduct is his own responsibility, and that he will be held accountable for all his conduct, whether positive or negative. [7] Moreover, to build trust and legitimacy police may engage in non-enforcement activities to show they are the guardian of the people and not a warring faction with the people.[8]

Safety and Security: The lowest net rating is on safety and security that includes the respondents feeling of safety and a better level of security in the area. It covers also the active campaign of the PNP against illegal drugs. Most or 79\% of the respondents in Albay showed favorable Safe and Security ratings to the PNP with a $6 \%$ unfavorable rating. These findings may be supported by the qualitative treatment of responses from the respondents. The respondents gave positive comments such as; "I am happy that many of our policemen still do their duties"; "I and my family feel secured to walk in the streets even at night because there are several policemen who roam around the area"; and "There is high security in our place". On the other hand, evident in the comments of the respondents from Daraga area and Tabaco City are the following complaints of the respondents: "They cannot fulfill their obligations"; "They do not roam around the vicinity"; "Traffic problems are not addressed"; and "Not very alert and delayed in making responses to crime scenes". Responsiveness of the policemen to the needs of the community is the cornerstone of peace, safety and security. The visibility of police officers in action in ensuring peace and order may etch in the minds of the community where they swore to defend and protect. Sometimes, police judgments on how to do things may compromise their actions. Thus, they need to have good judgment, careful and well-aligned strategies and procedures to avoid miscommunication and public distrust. Media may also play a role in delivering information about peace and order, safety and security to the community. When stories of unfortunate incidents between community and law enforcement are what the media magnifies, it can paint a negative and unfair picture of law enforcement leading to biased and low approval ratings from the public. It is noteworthy that the performance of the policemen in the locality should lead to a condition where there is less victimization, less fear of crime, lower perceived level of violent crime, lower perceived disorder in one's neighborhood, higher neighborhood cohesion and control. The media should not be a source of the negative opinion. Moreover, the community should not rely on the media for their opinions and responds and reacts primarily based on their own experiences and expectations of their local police.

Furthermore, there is a higher percentage or $15 \%$ of undecided rating on safety and security, followed by $13 \%$ undecided rating on trust. Respect had the lowest or 5.5\% undecided rating from Albayanos. These findings may be attributed to the respondents' fear of expression on issues they believed to be of high risks. However, it may be construed that these undecided ratings may be equated with unfavorable ratings. The respondents' undecided responses may also be attributed to the sector it belonged to, relationships with the police and its environment. The confidentiality treatment of the survey may not be enough to solicit the respondents' full trust and honest responses. Moreover, uninformed respondents generally choose the neutral option more often than the informed respondents. [9] 
Deri Ritzelda A., Gilbas Sherill A., and Dio Ryan V.

Table 4: Net Rating on Commitment of Support to the PNP

\begin{tabular}{|c|c|c|c|c|c|c|c|}
\hline Programs & Favorable & $\%$ & Unfavorable & $\%$ & Undecided & $\%$ & Net Rating \\
\hline Anti-illegal Drugs & 196 & $98.00 \%$ & 2 & $1.00 \%$ & 2 & $1.00 \%$ & $97.00 \%$ \\
\hline Anti-terrorism & 194 & $97.00 \%$ & 1 & $0.50 \%$ & 5 & $2.50 \%$ & $96.50 \%$ \\
\hline Anti-riding in Tandem & 193 & $96.50 \%$ & 2 & $1.00 \%$ & 5 & $2.50 \%$ & $95.50 \%$ \\
\hline Anti-illegal Gambling & 190 & $95.00 \%$ & 5 & $2.50 \%$ & 5 & $2.50 \%$ & $92.50 \%$ \\
\hline Average & 193.25 & $96.63 \%$ & 2.5 & $1.25 \%$ & 4.25 & $2.13 \%$ & $95.38 \%$ \\
\hline
\end{tabular}

The commitment of Support to the PNP: Table 4 reflects a 95.38\% net rating of the Albayanos on the commitment of support to the identified programs of the PNP. These programs are anti-illegal drugs, anti-terrorism, anti-riding in tandem and anti-illegal gambling. It can be noted that the highest net rating of support (97\%) is given to PNP's anti-illegal drugs program. Next to it is the anti-terrorism program with a $96.5 \%$ net rating, followed by anti-riding in tandem with a $95.5 \%$ net rating. The last is on an anti-illegal gambling program with a $92.5 \%$ net rating. These results are consistent with President Duterte's priorities on war against drugs and terrorism. The Philippines was placed in the international headlines on the issues of human rights violations due to the rampant killings of persons allegedly involved in drugs. Media men had aired several incidents of drug-related apprehensions and killings. This happening may be the result of the community's participation in the campaign against the administration's war against drugs. On the other hand, the declaration of martial law in the Mindanao area to topple the terrorist groups as well as the cancellation of peace talks with the New Peoples Army (NPA) may have contributed to this result of the commitment of support of the Albayanos to the anti-terrorism program of the PNP. In the survey, commitment to support the program against illegal drugs is higher in Daraga and Libon but lower in Bacacay and Tabaco. On the other hand, the program against terrorism is highest in Bacacay and Tabaco but lower in Daraga. They did not consider mentioning any statement of commitment towards the PNP in the open-ended question. As such, it can be considered that the comments given are on a one-sided basis as they complain yet do not sincerely compromise their part. Furthermore, the program against riding in tandem earned the highest commitment of support ratings from Bacacay and Tabaco but lowest in Libon. Moreover, the highest ratings of the commitment of support on program against illegal gambling were obtained from Bacacay while the lowest is from Libon and Tabaco. Existing problems and issues in the locality that impact so much on everyday existence must be treated and extracted immediately. Locations with the highest rate of disturbances may have given their highest commitment of support to the police officers to suppress the continuity and growth of such issues of disturbances, crimes and violations within their vicinity.

\subsection{THE NET RATINGS PER SECTOR ON TRUST, RESPECT, SAFETY AND SECURITY, COMMITMENT TO SUPPORT PNP PROGRAM}

It is interesting to note the net ratings of each sector regarding trust, respect, safety and security and the commitment of support to the PNP.

Trust: Table 5 shows the highest trust net ratings of $100 \%$ come from government elected officials and media. The lowest net rating of $50 \%$ is from the judiciary. The trust ratings given to PNP by the different sectors of the community seemed to focus on the nature of their respective work or professions. The $100 \%$ trust net rating is given by the elected government officials to the police may be attributed to the nature of how they got elected through a majority of even one (1) vote only. Not all voters appreciate or accept the system. Hence, officials need the PNP to secure them from any untoward incident that may be brought about by the system, especially while on the discharge of their elected duties. In fact, these officials may even request security services from either army or police. The media practitioners, likewise, need to trust highly the PNP. They need to gather data from the police, process these data and truthfully report the same to the citizenry through the various reporting medium. To get the truth, not the fake ones and to secure their own persons while gathering news, they have to highly trust the police. The judiciary on the other hand, maybe a little reluctant in their response to the survey, lest they may be seen as partial to the police. Again, it is the nature of their work that counts in order to dispense impartial judgment for all. Finally, employees in the private sector seemed to feel safer in their indecision rather than taking sides with regards to trusting the PNP. 
A Community Survey on The Performance of The Philippine National Police (PNP) In the Province of Albay

Table 5: Net Ratings Per Sector on Trust, Respect, Safety and Security and Commitment to Support the PNP’s Program

\begin{tabular}{|c|c|c|c|c|c|c|c|c|}
\hline \multirow[t]{2}{*}{ Sector } & \multirow[t]{2}{*}{$\mathrm{N}$} & \multirow[t]{2}{*}{ Trust } & \multirow[t]{2}{*}{ Respect } & \multirow{2}{*}{$\begin{array}{c}\text { Safety } \\
\& \\
\text { Security }\end{array}$} & \multicolumn{4}{|c|}{ Commitment to Support the PNP's Program } \\
\hline & & & & & $\begin{array}{c}\text { Anti-illegal } \\
\text { drugs }\end{array}$ & $\begin{array}{c}\text { Anti- } \\
\text { terrorism }\end{array}$ & $\begin{array}{l}\text { Anti-riding } \\
\text { in tandem }\end{array}$ & $\begin{array}{c}\text { Anti-illegal } \\
\text { gambling }\end{array}$ \\
\hline Academe & 20 & $65 \%$ & $90.00 \%$ & $60.00 \%$ & $95.00 \%$ & $100.00 \%$ & $95.00 \%$ & $90.00 \%$ \\
\hline Agricultural & 20 & $75 \%$ & $60.00 \%$ & $70.00 \%$ & $90.00 \%$ & $100.00 \%$ & $100.00 \%$ & $80.00 \%$ \\
\hline Business & 12 & $75 \%$ & $66.67 \%$ & $66.67 \%$ & $91.67 \%$ & $91.67 \%$ & $100.00 \%$ & $100.00 \%$ \\
\hline $\begin{array}{c}\text { Elected Govt } \\
\text { Official }\end{array}$ & 16 & $100 \%$ & $100.00 \%$ & $100.00 \%$ & $100.00 \%$ & $100.00 \%$ & $100.00 \%$ & $100.00 \%$ \\
\hline Govt Employee & 16 & $62.5 \%$ & $87.50 \%$ & $56.25 \%$ & $100.00 \%$ & $100.00 \%$ & $100.00 \%$ & $100.00 \%$ \\
\hline $\begin{array}{l}\text { Informal } \\
\text { Workers }\end{array}$ & 20 & $95 \%$ & $100.00 \%$ & $90.00 \%$ & $100.00 \%$ & $85.00 \%$ & $80.00 \%$ & $95.00 \%$ \\
\hline Judiciary & 4 & $50 \%$ & $100.00 \%$ & $50.00 \%$ & $100.00 \%$ & $100.00 \%$ & $100.00 \%$ & $100.00 \%$ \\
\hline Media & 4 & $100 \%$ & $100.00 \%$ & $100.00 \%$ & $100.00 \%$ & $100.00 \%$ & $100.00 \%$ & $100.00 \%$ \\
\hline Parents & 20 & $60 \%$ & $80.00 \%$ & $45.00 \%$ & $90.00 \%$ & $100.00 \%$ & $100.00 \%$ & $100.00 \%$ \\
\hline $\begin{array}{c}\text { Private } \\
\text { Employees }\end{array}$ & 16 & $62.5 \%$ & $81.25 \%$ & $37.50 \%$ & $100.00 \%$ & $93.75 \%$ & $100.00 \%$ & $100.00 \%$ \\
\hline Religious & 12 & $83.3 \%$ & $100.00 \%$ & $58.33 \%$ & $100.00 \%$ & $100.00 \%$ & $100.00 \%$ & $100.00 \%$ \\
\hline Transportation & 20 & $55 \%$ & $85.00 \%$ & $70.00 \%$ & $100.00 \%$ & $100.00 \%$ & $80.00 \%$ & $70.00 \%$ \\
\hline Youth & 20 & $65 \%$ & $90.00 \%$ & $60.00 \%$ & $100.00 \%$ & $90.00 \%$ & $100.00 \%$ & $90.00 \%$ \\
\hline
\end{tabular}

Respect: Table 5 also presents that the highest respect net ratings of $100 \%$ come from elected government officials, informal workers, judiciary, media and religious sectors. The lowest net rating of $60 \%$ is from the agricultural sector. These ratings suggest that respect for the police is somehow associated with the area-types where the respondents are based. It is likewise observed and confirmed that the more urbanized an area-type has become, the more populous with more varied concerns it will be. Consequently, an increased need for security and protection against the incidence of criminality and lawlessness is in order. The urban area is the usual domicile for the 5 sectors of respondents who had awarded the PNP with a perfect $100 \%$ respect - rating. This action may be their way to show gratitude and appreciation for the services rendered by the police to protect and secure them from lawless elements especially that a good number of these residents had fallen victims or witnesses to crimes perpetrated by said elements. The rural areas, on the other hand, are the usual home to the agricultural sector respondents. Considered as areas of peace and quiet where Filipino culture like bayanihan, camaraderie and others, are still in existence, the presence of the police is limited and scarce, if not nil. Incidents of criminality committed by some elements wherein some still posing as police have remained unsolved for sometime. This may be the reason behind the low respect rating given to the PNP by the sector.

Safety and Security: Table 5 also reflects that the highest safety and security net ratings of $100 \%$ come from the elected government officials and media. The lowest net rating of $37.50 \%$ is from the Private employee sector. Moreover, only two 2 sectors of the respondents had accorded the PNP with a 100\% net rating for safety and security. This perfect rating or higher need for security and safety of the elected government officials and media practitioners may be explained by their placement in the community's social structure as well as the nature of their work. On the other hand, the sector of the private employees, feeling insecure, unsafe and powerless for their being private and ordinary citizens of the community who oftentimes had fallen victims to crimes and other unlawful activities of lawless elements had allotted the lowest net rating for safety and security. This indicates that the support acquired from the community depends on the quality of personal experience with the police. [9]

Commitment to Support PNP Programs along Anti-illegal drugs, Anti-terrorism, Anti-riding in tandem and Anti-illegal gambling: Table 5 also reveals the highest net rating (100\%) of support to PNP's anti-illegal drugs program comes from elected government officials, government employees, informal workers, judiciary, media, private employees, religious, transportation and youth sectors. The lowest net rating (90\%) comes from the agricultural and parent sectors. The highest net rating (100\%) of support to PNP's anti-terrorism program comes from academe, agricultural, elected government officials, government employee, judiciary, media, parents, religious, and transportation sectors. The lowest net rating (85\%) comes from informal workers. The highest net rating 
Deri Ritzelda A., Gilbas Sherill A., and Dio Ryan V.

(100\%) of support to PNP's anti-riding in the tandem program comes from agricultural, business, elected government officials, government employee, judiciary, media, parents, private employees, religious, and youth sectors. The lowest net rating (80\%) comes from informal and transportation workers. The highest net rating (100\%) of support to PNP anti-illegal gambling program comes from business, elected government officials, government employees, judiciary, media, parents, private employees and religious sectors. The lowest net rating (70\%) comes from transportation workers.

\subsection{RECOMMENDATION OF THE RESPONDENTS RELATED TO PNP PROGRAM AND SERVICES}

There are various recommendations that the respondents have given. They can be categorized on trust, respect, safety and security. Most of the recommendations given are focused on safety and security. The following are recommended several times by the respondents. The top recommendations include: Police visibility to public places and 24/7 police patrol; "There should be checkpoint at least once a week to ensure safety in the community"; "Curfew must be implemented in the barangay even if it has distance from the town proper"; and "Policemen should have fair treatment to everyone". Some respondents also recommended to continue and maintain the good program/service of the PNP. Moreover, others suggested that some policemen need continuous training, particularly the Junior policemen. They also added that there can be monthly consultation so that the police will be informed of the need of the community. On the category of Respect, some respondents suggested that some policemen should avoid drinking and gambling. The proposition that the policemen should attend training is also reiterated by some respondents in this statement: "Training and schooling for better management".

In the nutshell, it can be stated that the respondents commit themselves to cooperate with the PNP. It can be deemed from their suggestions that they are willing to submit to the programs like curfew, traffic and even consultation, which means discussions of things for more peaceful, friendly and nice-to live with the community.

\section{CONCLUSIONS AND RECOMMENDATIONS}

In the light of these findings, the Albay PNP was assessed by the Albayanos to have high approval ratings in the performance of their duties. They earned high approval ratings on trust, respect, safety and security. Community's commitment to support to their programs has achieved high ratings too. Although there are positive comments that strengthen the community's confidence in the PNP, the negative comments are more important to note so as to improve the PNP as an organization and its delivery of services to the optimum level. The level of trust that the Albayanos had for the PNP should be maintained and enhanced so as to warrant a higher level of respect from among them. Getting feedback and recommendations from the community may also help in building trust and confidence that will be translated into strong public support. Any endeavor of peace, order, safety, and harmony can be easily achieved in partnerships, collaboration, and cooperation that are built on trust and respect.

\section{SOURCES OF FUNDING}

This research received no specific grant from any funding agency in the public, commercial, or not-for-profit sectors.

\section{CONFLICT OF INTEREST}

The author have declared that no competing interests exist.

\section{ACKNOWLEDGMENT}

The authors acknowledge the PNP ROV for funding the conduct of the survey. 
A Community Survey on The Performance of The Philippine National Police (PNP) In the Province of Albay

\section{REFERENCES}

[1] PNP NegOr (2017) "PNP Negor Resumes Online Survey Performance Evaluation" (http://www.sunstar.com.ph/dumaguete/local-news//pnp-negor-resumes-online-survey-performanceevaluation, 2017)

[2] Mateo, J. (2017) "Poll shows record-high trust for AFP, PNP"

[3] Country meters (2018) “Live Philippines population (2018)". www.countrymeters.info Retrieved July 2018

[4] Philippine Statistics Association (2016) "Women and Men in the Philippines" A Handbook 2016, PSA https://psa.gov.ph

[5] Philippine Statistics Association (2016) "Marriage in the Philippines", PSA 2016 https://psa.gov.ph

[6] Roufa, Timothy (2018) Ethics in Law Enforcement and Policing Updated April 15, 2018 https://www.thebalancecareers.com

[7] IACP (2009) "Building Trust Between the Police and the Citizens They Serve: An Internal Affairs Promising Practices Guide for Local Law Enforcement" Office of Community Oriented Policing Services (the COPS Office), U.S. Department of Justice, and the International and National Criminal Justice Reference Service, https://www.ncjrs.gov retrieved June 2018

[8] National Institute of Justice (2003). Building Trust To Law Enforcement Though Service, (https://www.firescience.org retrieved July 2018)

[9] Lam, Allen \& Green (2010) Paper presented at the annual meeting of the National Council on Measurement in Education, Denver, CO, May 2010. www.ncme.org/

[10] Boateng, F.D. (2018) Crime Reporting Behavior: Do Attitudes Toward the Police Matter? Journal of Interpersonal Violence, volume 33 issue: 18 page(s) 2891-2916 Retrieved https://journals.sagepub.com 